\title{
Nurses' Voluntary Turnover during Early Hospital Career as Predicted by Depressive Symptoms and Anxiety Symptoms
}

\author{
Meyrav Marom ${ }^{1,2} \&$ Meni Koslowsky ${ }^{3}$ \\ ${ }^{1}$ School of Business Administration, Lander College, Jerusalem Academic Center, Jerusalem, Israel \\ 2 The David Yellin Academic College of Education, Jerusalem, Israel \\ ${ }^{3}$ Department of Psychology, Bar-Ilan University, Ramat-Gan, Israel \\ Correspondence: Meyrav Marom, School of Business Administration, Lander College, Jerusalem Academic \\ Center, 3-5 Am Veolamo St., P.O.B. 34353, Jerusalem 91343, Israel. E-mail: eli159@bezeqint.net
}

Received: February 11, 2012

doi:10.5539/ijps.v4n2p188

\begin{abstract}
Using a longitudinal design, this study examined the unique effects of depressive symptoms and of anxiety symptoms on voluntary turnover of nurses during the early stage of their hospital career. We hypothesized that depressive symptoms would negatively predict turnover and that anxiety symptoms would positively predict turnover after controlling for their common variance. We also hypothesized the same effects for depressive and anxiety symptoms when assessed as changes over time. We collected longitudinal data from 201 newly employed hospital nurses in 25 general hospitals who completed questionnaires with a time lag of about six months at Time 1 (T1) and Time 2 (T2). To gauge turnover, we used the official hospitals' records at Time 3 (T3), about one year after the study's T1. Logistic regressions were used to test our hypotheses. As expected, we found that T2 anxiety symptoms increased the odds of the nurses' turnover while T2 depressive symptoms decreased it. As expected, the higher the increase between T1 and T2 in depressive symptoms, the lower the odds of the nurses turnover. However, we did not support the expectation that the T1 to T2 changes in anxiety symptoms would predict turnover positively. We suggest that the unique content of depression and anxiety differ markedly in their effects on quitting behavior.
\end{abstract}

Keywords: voluntary turnover, depression, anxiety, longitudinal study, hospital nurses

\section{Introduction}

As a general shortage of nurses is a public health problem in many countries, the retention of currently available nursing staff has become a major challenge to employers. As noted by a recent meta-analytic study (Zimmerman, 2008), past studies on the predictors of turnover have focused on those representing work-related characteristics and attitudes such as job satisfaction - an important predictor of turnover (Griffeth, Hom \& Gaertner, 2000) and have paid less attention to affective states and traits as its putative causes. Those studies that did include both depressive symptoms and anxiety symptoms as predictors of turnover often combined them to represent negative affectivity ( $\mathrm{Ng} \&$ Sorensen, 2009) or subsumed them under the personality trait of neuroticism (Zimmerman, 2008) and thus assessed the effects of the general factor of Negative Affect (Watson, 2000) on turnover behavior. The major objective of this study is to examine the unique effects of depressive symptoms and anxiety symptoms on nurses' actual turnover behavior. Based on the Tripartite Model of Anxiety and Depression (Watson, 2000), we propose that the unique characteristic of each depressive symptoms and anxiety symptoms - after controlling for the variance they share with the general factor of negative affect - will independently be linked with quitting behavior.

The unfolding model of employee turnover (Tifferet, Elizur, Constantini, Friedman \& Manor, 2008) proposes that negative affect, including depressive symptoms and anxiety symptoms, leads to an employee decision to leave the employing organization even without considering any alternatives (p. 69). The study by Thoresen and his colleagues (Thoresen, Kaplan, Barsky, Warren \& Chermont, 2003) suggests, based on its meta-analytic findings, that negative affect, either assessed as a trait such as neuroticism or as a state such as depression and anxiety, is likely to result in uncritical turnover behavior. Turnover behavior directly related to negative affects has been found to represent an important category of quitting employees (Maertz \& Griffeth, 2004). Supporting the unfolding model of employee turnover, this empirical study (Maertz \& Griffeth, 2004) found that 
experiencing strong negative affect often causes a flight mechanism that precludes rational consideration of alternative employment. Therefore, there is a body of theory and empirical research in the field of turnover supporting the assertion that negative affect and turnover behavior are indeed closely associated.

In many past studies, conducted with different measures of depressive and anxiety symptoms and on diverse samples, depression and anxiety were found to be closely associated (Shankman \& Klein, 2003). Substantial comorbidity has also been observed at the clinical diagnostic level (Mineka, Watson \& Clark, 1998). The empirical overlap between depression and anxiety is explained by their representing two facets of the higher-order general factor of neuroticism or negative affectivity (Watson, 2000). Anxiety and depression share the common factor of negative affectivity or distress. Watson's Tripartite Model of Anxiety and Depression (Watson, 2000) posits that over and above their shared or common variance, depression and anxiety each has its own unique characteristics. For depression, this unique characteristic is represented by being unable to experience pleasure and low positive affect, not shared with anxiety. For anxiety, this unique characteristic is represented by hyperarousal, not shared with depression. There is a body of evidence supporting the Tripartite Model (Anderson \& Hope, 2008; Bedford, 1997; Clark \& Watson, 1991; Howren \& Suls, 2011; Watson, 2000). Following this model, we propose that for persons reporting anxiety symptoms, the distinctive cognitive signature is hypervigilance for potentially threatening stimuli, leading them to react, including behaviorally, to potentially negative stimuli in their immediate environment (Howren \& Suls, 2011). For persons reporting depressive symptoms, the distinctive cognitive signature is loss of interest and intensive self-focus (Howren \& Suls, 2011). Anxiety symptoms and depressive symptoms have been found to differentially predict health outcomes (Kubzansky, Cole, Kawachi, Vokonas, \& Sparrow, 2006; Stewart, Janicki, Muldoon, Sutton-Tyrrell, \& Kamarck, 2007). For example, while depressive symptoms place patients with coronary heart disease at subsequent risk of morbidity and mortality, this is not the case with anxiety symptoms (Suls \& Martin, in press).

\subsection{The Study's Hypotheses}

To test the Watson's (2000) Tripartite Model, we controlled for anxiety symptoms when testing hypotheses that concern depressive symptoms and controlled for depressive symptoms when testing hypotheses that concern anxiety symptoms. Why should the unique characteristic of anxiety symptoms, hypervigilence and hyperarousal, predict turnover behavior? Based on the turnover process model suggested by Mobley et al. (Mobley, Griffeth, Hand \& Meglino, 1979), we argue that individuals feeling negatively aroused may translate these feelings into thoughts of quitting and ultimately quitting, in the expectation that they will find a job which is less anxiety provoking. Additionally, anxious employees are more likely to become involved in interpersonal conflicts (Cote, 2005). There is evidence that during the early career stage, when they have to learn and perform new job responsibilities and become socialized into a new work environment, most job demands are ambiguous and uncertain (Zimmerman, 2008) and therefore likely to cause hypervigilence regarding environmental cues (Judge, 1993).

Why should the unique characteristic of depressive symptoms predict turnover behavior? As the Tripartite Model posits, the unique characteristic of depressive symptoms is low positive affect and a negative attitude toward life. Based on this theoretical argument, we argue that because of the negative attitude toward life persons with depressive symptoms are less likely to consider quitting and actually quit their jobs. For those high on depressive symptoms, quitting is hardly likely to be viewed as improving their job prospects. There is some empirical support for this argument in Judge (1993), who found that those with a negative disposition to life are less likely to take action and quit. Accumulated evidence suggests that depressed persons tend to be risk averse and tend to withdraw from activities, including those that may be rewarding (Smoski et al., 2008).

As suggested in a major review of the area (Mobley et al., 1979), changes over time in the predictors of turnover behavior should be included in the design of studies explaining it because processes of quitting behavior are dynamic and change over time. This theoretical argument appears more valid when considering samples of new employees who gradually gain experiences and learn more effective coping behaviors. This socialization process could alter their affective reactions to changing job circumstances. Thus, for new employees, depressive and anxiety symptoms may change across their first year of work because of environmental factors. Still, genetic factors have been found to underlie the etiology of both anxiety and depressive symptoms (Suls \& Bunde, 2005). It has been suggested that the aforementioned comorbidity of anxiety and depressive symptoms is in part due to heritable factors (Eley \& Stevenson, 1999). Therefore, we based our third hypothesis on the theoretical arguments presented above. We formulated our third hypothesis again focusing only on the unique content of depressive symptoms and anxiety symptoms - that is, controlling for the variance they share with each other. In addition, we controlled for the initial levels of individuals' levels of anxiety and depressive symptoms, thereby investigating the effects of changes in them from the initial levels to those of the follow-up (T2) on the 
subsequently assessed quitting behavior.

For several reasons, this study focuses on nurses during their first months of work in a hospital. First, this period is usually one of high levels of psychological strain because of the need to learn new tasks and adapt to new demands while maintaining acceptable levels of performance (Elfering, Semmer, Tschan, Kalin, \& Bucher, 2007; Taris \& Feij, 2004). It is a period of new challenges and stresses with important consequences for an employee's future career (Saks \& Ashforth, 2000). Indeed, nurses in their initial months of work in hospitals have been found to report high levels of psychological strain at work, relative to veteran nurses (Gelsema, van der Doef, Maes, Akerboom \& Verhoeven, 2005; Gelsema et al., 2006). Second, studying a cohort of new entrants in an organization controls to a large extent for the potential confounders of organizational tenure and level, both of which tend to be associated turnover (Griffeth et al., 2000). We decided to study nurses upon entrance to their new hospital work role and a few months later to determine the influence of our predictors on their actual turnover behavior during this period of time.

In testing our hypotheses, we controlled for demographic predictors expected on the basis of past theory (Mobley et al., 1979) and accumulated evidence (for a recent review, see: Wagner, 2010) to influence turnover behavior gender, age, marital status and educational attainment.

According to the rational stated above, our three hypotheses are:

Hypothesis 1: We argue that anxiety symptoms will be a positive predictor of turnover behavior.

Hypothesis 2: We argue that depressive symptoms will be a negative predictor of turnover behavior.

Hypothesis 3: We argue that after controlling for T1 levels of anxiety symptoms and depressive symptoms, the higher the T2 anxiety symptoms and the higher the T2 depressive symptoms, the higher and lower actual turnover, respectively.

\section{Method}

\subsection{Participants}

The present study used a three-wave longitudinal design and included newly-employed nurses who were employed in one of 25 acute-care non-profit hospitals in Israel. The sampling frame consisted of 30 acute-care non-profit hospitals with 100 beds; out of them, 25 agreed to participate with the study by providing the researchers with names and addresses of newly employed nurses in them. The Time 1 (T1) and Time 2 (T2) waves consisted of questionnaires sent to nurses, while T3 wave consisted of requests to the head nurse of each hospital to indicate the job status of each participant in our study. The T1 questionnaire was sent to 324 nurses who appeared on the hospitals' employee rosters and who had joined the staff during the five months prior to the study. From this group, 234 questionnaires were returned, a response rate of $72 \%$. The T2 study questionnaire was sent to all those who responded to our T1 questionnaire; of these 201 responded and they made up the present study's sample. This response rate, approximately $60 \%$, is considered quite satisfactory (Baruch \& Holtom, 2008). The nurses were employed primarily in the internal medicine (18\%), surgical (17\%), intensive care $(17 \%)$ and pediatric $(9 \%)$ wards, with minor concentrations in the orthopedic and gynecology wards. However, because it is customary for some acute-care non-profit hospitals to rotate nurses among several wards during their first year of work, we did not use the ward as a control variable.

In order to test for a systematic bias caused by the attrition of respondents from $\mathrm{T} 1 \quad(\mathrm{~N}=234)$ to $\mathrm{T} 2(\mathrm{~N}=201)$, analyses were conducted to examine the significance of the difference in the depressive symptoms and anxiety symptoms at $\mathrm{T} 1$ between subjects who responded to both $\mathrm{T} 1$ and $\mathrm{T} 2$ questionnaires and those who responded only at T1. No significant difference was found between these two groups on either of the criteria. In addition, an examination of the significance of the difference on approximately 20 socio-demographic variables between the two groups showed a significant difference only on the measure of educational attainment or schooling. This difference can be explained as a chance result, leading us to conclude that there was no systematic bias due to the attrition. Still, educational attainment was used as a control variable in our analyses.

The final sample participants comprised mostly women (90\%) with a mean age of 27.4 years. About $5 \%$ of the participants were nurse practitioners, $57 \%$ were registered nurses, and $32 \%$ were registered nurses who also had an academic degree in nursing. Among the participants, $63 \%$ had no children, $75 \%$ were nurses new to the profession, and 54\% were born in Israel with the rest coming from countries worldwide.

\subsection{Measures}

The intercorrelations, means, and standard deviations for each variable included in our model are presented in Table 1. A measure of internal consistency (Cronbach's alpha) was used to assess the reliability of the multi-item 
measures included in the current study.

Table 1. Inter-correlations, means and standard deviations of the study's variables

\begin{tabular}{|c|c|c|c|c|c|c|c|c|c|}
\hline Measure & 1 & 2 & 3 & 4 & 5 & 6 & 7 & 8 & 9 \\
\hline 1. Turnover T3 ( $0=$ stayed, $1=$ left $)$ & - & & & & & & & & \\
\hline 2. Depressive symptoms, $\mathrm{T} 2$ & -.11 & - & & & & & & & \\
\hline 3. Anxiety symptoms, $\mathrm{T} 2$ & .01 & .67 & - & & & & & & \\
\hline 4. $\quad$ Gender $(1=$ men $)$ & .16 & -.07 & -.09 & - & & & & & \\
\hline 5. Age & -.07 & -.20 & -.26 & .02 & - & & & & \\
\hline 6. $\quad$ Marital status $(1=$ married $)$ & .01 & -.19 & -.12 & -.04 & 46 & - & & & \\
\hline 7. Educational attainment &.$\underline{04}$ &.$- \underline{.08}$ &.- .01 & .05 &.$\underline{02}$ & .06 & & & \\
\hline 8. Depressive symptoms, $\mathrm{T} 1$ & .11 & .57 & .59 &.$- \underline{03}$ & -.07 & -.19 & -.06 & - & \\
\hline 9. Anxiety symptoms, $\mathrm{T} 1$ & .12 & .47 & .62 & -.07 &.$- \underline{05}$ & .05 & -.01 & .68 & \\
\hline Means & .14 & 2.55 & 2.75 & .10 & 27.45 & 1.65 & 3.01 & 2.58 & 2.73 \\
\hline Standard deviations & .35 & .83 & .72 & .29 & 5.69 & .55 & .58 & .86 & .72 \\
\hline
\end{tabular}

Note. $\mathrm{N}=193$. Accepting those underlined, all coefficients are statistically significant at the $\mathrm{p}<.05$ level.

Gender was codes as $0=$ women and $1=$ men, while marital status was coded as $0=$ single and $1=$ married.

Turnover. The data on turnover was obtained from the head nurses files at each hospital about six months following the T2 questionnaire; during the T2-T3 period, 30 nurses left their hospital jobs volunatrily.

Depressive Symptoms and Anxiety Symptoms. We conceptualized depressive and anxiety symptoms following Veit and Ware (1983) who defined them as two primary factors in their construct of psychological distress, as assessed by their Mental Health Inventory (MHI). All MHI items refer participants to their feelings during the last month; the MHI is state-oriented. The MHI consists of three subscales, namely depressive symptoms, anxiety symptoms, and loss of control. All subscales have been validated for use both as separate factors and as a total score gauging psychological distress. We focused on only depressive and anxiety symptoms. The measure of anxiety symptoms was assessed by 8 items (for example, "I felt anxious"; I felt tension": "I felt resitless"), with $\alpha=.88$ at both T1 and T2. The measure of depressive symptoms was assessed by five items (for example, "I was in a depressed mood"; "I felt lonely"; "I felt sad") with $\alpha=.86$ and .77 at T1 and T2, respectively. The MHI and its factors were validated in Hebrew (Florian \& Drory, 1990). This scale, and its factors of depressive symptoms and anxiety symptoms, has been used in many studies thus supporting their construct validities (Berant, Mikulincer \& Shaver, 2008; Lavidor, Weller \& Babkoff, 2002). Therefore, there is considerable support to the claims of Veit and Ware (1983 and of Florian \& Drory (1990) that the depressive symptoms and anxiety symptoms subscales of the MHI can be used as distinct variables.

Control variables. Following the general recommendations in the turnover literature (Griffeth et al., 2000) we used four control variables: gender, age, marital status, and educational attainment as reported by the participants at $\mathrm{T} 1$.

\subsection{Procedure}

The study was approved by the Bar Ilan's University Helsinki Committee. After receiving the roster of nurses who had started working over the previous five months, we mailed the T1 questionnaires to them. The importance of the study was explained, and full confidentiality was assured, but we requested that participants include their names and addresses to enable the researchers to mail them at a point of time the second questionnaire. The accompanying letter emphasized that the study was for research purposes and was unconnected to the hospital, pledging that no one in the hospital would see the filled-out questionnaires. In addition, respondents to both questionnaires were paid the equivalent of $\$ 20$ in local currency. Providing payment is known in the literature as an efficient method of increasing response rate to surveys (Church, 1993). Two versions of the questionnaire were randomly sent to the participants at T1 and T2; in each version the sub-questions were arranged in a different order to prevent primacy or order effects. T2 measurement was performed six months after $\mathrm{T} 1$. At $\mathrm{T} 3$, about one year after the mailing of the $\mathrm{T} 1$ questionnaire, a letter was sent 
to the head nurses of the participating hospitals asking them to describe the present position of each nurse who responded to the T2 questionnaire. The head nurses were asked to state clearly if any of the participants voluntarily left the hospital.

\subsection{Analytic Methods}

We used logistic regressions to test our hypotheses. A standard level of significance, $\mathrm{p}<.05$, was used, and was assessed in the logistic regressions via Wald test using SPSS version 19.0. Depressive symptoms and anxiety symptoms are both facets of the higher order construct $\mathrm{f}$ neuroticism, and therefore are closely associated; their intercorrelation may sometimes exceed .70 (Wetherell, Gatz \& Pedersen, 2001). Therefore, it is necessary to test our hypotheses while simultaneously entering both predictors into the logistic regression predicting turnover behavior. Prior to our analyses, we centered all T1 and T2 predictors to reduce collinearity as this transformation does not have any effect on the value of the logistic coefficients and their estimated standard errors (Jaccard, 2001). A rough guideline to detect collinearity in logistic regressions is unstandardized logistic regression coefficients greater than 2 (Menard, 2010, p. 127); as evident from Table 2, these coefficients are all smaller than 2. We first tested Hypotheses 1 and 2 using T2 depressive and anxiety symptoms, and the control variables, to predict T3 turnover. In Table 2, the results are referred to as Model 1. We then tested Hypothesis 3 by adding to the above set of predictors T1 depressive symptoms and anxiety symptoms. Adjusting the regression for the baseline symptoms of anxiety and depression has been recommended to assess change from baseline to follow-up (Twisk, 2003). The results appear under Model 2 in Table 2.

Table 2. Logistic regressions predicting voluntary turnover

\begin{tabular}{|c|c|c|c|c|c|c|}
\hline \multirow{2}{*}{ Predictor } & \multicolumn{3}{|c|}{$\underline{\text { Model 1: Only T2 Predictors }}$} & \multicolumn{3}{|c|}{ Model 2: T1 and T2 Predictors } \\
\hline & $\mathrm{b}$ & SE & Odds ratio & $\mathrm{b}$ & $\mathrm{SE}$ & Odds ratio \\
\hline \multicolumn{7}{|l|}{ Predictors, T2 } \\
\hline Depressive symptoms & -.96 & .35 & $.39^{*}$ & -1.17 & .41 & $.32 *$ \\
\hline Anxiety symptoms & .70 & .32 & $1.82 *$ & .33 & .42 & 1.40 \\
\hline Gender & -1.30 & .66 & $.27 *$ & -1.26 & .68 & .28 \\
\hline Age & -.03 & .05 & .98 & -.04 & .05 & .96 \\
\hline Marital status & .10 & .44 & 1.07 & .18 & .59 & 1.20 \\
\hline Educational attainment & .09 & .30 & 105 & .03 & .31 & 1.03 \\
\hline \multicolumn{7}{|l|}{$\underline{\text { Predictors, } \mathrm{T} 1}$} \\
\hline Depressive symptoms & & & & .59 & .35 & 1.80 \\
\hline Anxiety symptoms & & & & .14 & .37 & 1.15 \\
\hline
\end{tabular}

Note: $\mathrm{N}=193$; between $\mathrm{T} 2$ and $\mathrm{T} 3,30$ nurses quitted their hospital job. In the table, $\mathrm{b}$ refers to the unstandardized logistic regression coefficients while SE refers to their standard error. Summary statistics for Model 1 and 2: $-2 \log$ likelihood $=115.8^{*}, 107.6^{*}$, respectively, and percent correctly classified $=87 \%$ and $88 \%$, respectively.

\section{Results}

Table 1 presents the means, standard deviations, and inter-correlations of the study's variables. While no specific hypothesis was formulated in this regard, the T1 levels of both depressive and anxiety symptoms were not significantly different from their T2 levels; however, they were not significantly correlated with voluntary turnover. Turnover is a dichotomous variable, and therefore Pearson correlations under-estimate its correlations 
with other variables. Using coefficient Eta to assess relationships between a nominal dependent variable and an interval predictor, we found that the associations among $\mathrm{T} 1$ and $\mathrm{T} 2$ anxiety and depressive symptoms and turnover behavior were all significant and above .30. As found in many studies (Suls \& Bunde, 2005), anxiety and depressive symptoms were closely correlated, indicating that they share some of their content as reflected in the conceptualization of negative affectivity (Ng \& Sorensen, 2009) or neuroticism (Shankman \& Klein, 2003). Still, in the analyses reported below both predictors were entered simultaneously and therefore their unique rather than shared content predicted turnover behavior. The stability coefficients or T1-T2 correlations of depressive symptoms and anxiety symptoms were on the average $r=.59$, consistent with stability coefficients reported for other work-related affective states (Luthans, Avolio, Avey \& Norman, 2007) but still considerably below the stability coefficients found for personality traits (Watson \& Walker, 1996).

Table 2 presents the results of the logistic regressions run to test our hypotheses for Model 1 (only T2 predictors and control variables) and Model 2 (T2 predictors, control variables and T1 predictors). In both, the control variables used - gender, age, marital status and educational attainment - were not statistically significant predictors of the nurses' quitting behavior, a result consistent with those reported in the most recent meta-analytic study of the predictors of turnover (Griffeth et al., 2000). With respect to the T2 predictors in Model 1, there was strong support for our hypotheses in that after controlling for the control variables, depression decreased and anxiety increased the odds of nurses' quitting their job. Holding the other variables in Table 2 constant, for each one-unit increase in anxiety symptoms the odds of quitting go up on average by a multiplicative factor - referred to in Table 2 as the odds ratio - of 1.82. Similarly, for each one-unit increase in depressive symptoms, the odds of quitting change by multiplicative factor of .39. Because this factor is less than one, as depressive symptoms increase, the odds of turnover decrease. Therefore, Model 1 in Table 2 provides strong support for our Hypotheses 1 and 2 on the effects of T2 depressive symptoms and T2 anxiety symptoms, respectively, on turnover behavior.

Before testing the specific predictions formulated by Hypothesis 3, $\chi^{2}$ difference test was used to address the question of the added value of Model 2 to the prediction of turnover. The results of the $\chi^{2}$ difference test (Model $1, \chi^{2}=46.1$, d.f. $=7$; Model 2, $\chi^{2}=53.2$, d.f. $=10$ ) indicated that Model 2 is not significantly different from Model 1. Therefore, we can not claim any support for Hypothesis 3. Still, the directionality of the effects of the T2-T1 changes in the levels of depressive symptoms and anxiety symptoms on the odds of turnover was found to be consistent with the third hypothesis, though only T2 depressive symptoms reduced the odds of turnover after its T1 level and the other variables included in Model 2 were controlled (Model 2, Table 2).

\subsection{Exploratory Results}

Our hypotheses were based on Watson's (2000) Tripartite Model and therefore we focused on the unique contribution of depressive symptoms and anxiety symptoms to the prediction of turnover behavior, controlling for one another in our logistic regression. Using the same set of controls as reported in Table 2, we ran several additional exploratory analyses. For each participant, negative affectivity was defined as the average of his or her mean scores on depressive symptoms and anxiety symptoms. When thus combining depressive symptoms and anxiety symptoms to represent negative affectivity, it was not a significant predictor of turnover behavior at either T2 or T1. Again on an exploratory basis, we used depressive symptoms but removed anxiety symptoms in predicting turnover behavior. T2 depressive symptoms was a significant predictor of turnover behavior, with odds ratio $=.61$. We then used anxiety symptoms as a predictor, removing depressive symptoms. Anxiety symptoms were not a significant predictor of turnover behavior at either T2 or T1. These exploratory results provide additional support to Watson's (2000) Tripartite Model in that it is only after controlling for the common variance that depressive symptoms and anxiety symptoms share with one another that their unique contribution to the prediction of turnover behavior unfolds, as reported above.

\section{Discussion}

The study's findings support the view that depressive symptoms and anxiety symptoms each has a unique component which make a unique contribution to the prediction of behavioral consequences such as turnover (Howren \& Suls, 2011). We found that depressive and anxiety symptoms are closely correlated and therefore often subsumed under the aegis of negative affectivity ( $\mathrm{Ng} \&$ Sorensen, 2009). Still, when focusing on the unique features of depressive symptoms and anxiety symptoms, after controlling for the variance which they share with one another, we found them to have diametrically opposite effects on turnover behavior, as predicted by Watson's Tripartite Model of Depression and Anxiety. Anxiety symptoms increased while depressive symptoms decreased the odds of turnover. Therefore, we suggest that future studies on the role of negative affects in explaining turnover behavior use measures of depressive and anxiety symptoms which cover both their 
common and unique aspects. We were not able to show that this set of findings is fully replicated across time, when using the T1-T2 changes in the levels of depressive and anxiety symptoms as predictors of quitting behavior. Still, the general trend which emerges (Model 2, Table 2) is consistent with our expectations as formulated in Hypothesis 3, though the effect of the T1-T2 change in anxiety symptoms on the criterion was not significant. Our hypotheses were tested on a relatively homogeneous, almost all-female participants newly employed as hospital nurses. Overall, our results highlight the (expected) importance of anxiety symptoms as increasing the odds of quitting behavior over and above the contribution of depressive symptoms to the prediction of turnover.

Our findings are analogous to those of an experimental study (Moon, Hollenbeck, Humphrey \& Maue, 2003), that found anxiety and depression, when simultaneously used as predictors of escalating commitment, were positively and negatively associated with this criterion. It provides support to the theoretical view that individuals' affective reactions are associated with quitting behavior and further joins the empirical studies reviewed above which supports this theoretical view (Kashdan, 2004; Larsen \& McGraw, 2011).

It could be that our failure to find support for the third hypothesis is due to a finding reported in the literature on nurses' turnover that the more proximate is a predictor to actual turnover, the more powerfully it predicts turnover relative to other predictors more distal in time from quitting behavior (Kopelman, Rovenpor \& Millsap, 1992). A possible statistical reason for the lack of support for our third hypothesis dealing with the effects of changes in the levels of depressive and anxiety symptoms on quitting behavior may be the relative stability of both measures across time. As noted, there was no T1-T2 statistically significant difference in the means of either depressive or anxiety symptoms.

The present study has several strengths. First, the relatively high response rate obtained in the study in comparison with other longitudinal studies (Ployhart \& Vandenberg, 2010) adds a degree of meaningful external validity to the specific population that was sampled. Second, the two types of negative affect were measured simultaneously and were examined at two separate times, using a longitudinal design. Third, the scales assessing depressive and anxiety symptoms were carefully examined to ensure that they possess discriminant validity. Fourth, we attempted to enhance the study's internal validity by applying a variety of techniques. The longitudinal data were measured at meaningfully spaced intervals: T1 was the time the nurses entered their new, mostly first, hospital job and T2 was about six months later, while quitting behavior was assessed at T3, about a year after $\mathrm{T} 1$.

The present study has a number of limitations. The findings' external validity in occupational settings other than nursing needs to be established in additional research. Because the participants were young females in their reproductive years, our findings need to be replicated in samples representing the other gender and age groups. Additionally, while we asked each head nurse responding to our third wave of data gathering to include in the lists of quitting nurses only those that had done so voluntarily, we could not verify their accounts by other means. Still, in view of the nature of our theoretical arguments, we argue that the inclusion of a few nurses who quitted involuntarily in the lists of quitting nurses is unlikely to attenuate our findings. Future research may examine the extent to which voluntary versus involuntary quitting moderates the effects we found. We did not use measures of depressive and anxiety symptoms specifically designed to assess separately their common and unique elements (Larsen \& McGraw, 2011). In the current research, we used the symptoms of anxiety and depression as included as facets in the MHI.

Our findings suggest that future research on anxiety and depression predicting employee behavior should consider paying attention to the unique, non-overlapping aspects of each as demonstrated in our study. These unique aspects, as proposed by Watson' Tripartite model, should be included in instruments assessing depressive symptoms and anxiety symptoms. For example, to validly assess the contribution of anxiety symptoms to the prediction of behavior, researchers should pay attention to include among other symptoms of anxiety those reflecting hyperarousal. The study findings have some practical implications also. To be cost-effective, interventions designed to reduce nursing turnover could focus on negative affect such as anxiety and depression, making sure that the measures used to assess anxiety and depression include the items allowing focus on their unique features. Depressive symptoms have been associated with a variety of health outcomes (Shin, Suls \& Martin, 2008; Suls \& Bunde, 2005), and for this reason reducing their levels should be considered an important priority for those at the helm of organizations striving to improve employee health.

It is hoped that this study will serve as a catalyst for future research that examines important differences among specific facets of neuroticism or negative affectivity in the prediction of behavioral outcomes. Future research may consider the possibility of adding to the models examined in the current study possible mediators that may 
transmit the influence of the negative affects investigated onto turnover, such as job satisfaction, organizational commitment and job performance (Zimmerman, 2008).

\section{References}

Anderson, E. R., \& Hope, D. A. (2008). A review of the tripartite model for understanding the link between anxiety and depression in youth. [Review]. Clinical Psychology Review, 28(2), 275-287. http://dx.doi.org/10.1016/j.cpr.2007.05.004

Baruch, Y., \& Holtom, B. C. (2008). Survey response rate levels and trends in organizational research. Human Relations, 61(8), 1139-1160. http://dx.doi.org/10.1177/0018726708094863

Bedford, A. (1997). On Clark-Watson's tripartite model of anxiety and depression. Psychological Reports, 80(1), 125-126. http://dx.doi.org/10.2466/pr0.1997.80.1.125

Berant, E., Mikulincer, M., \& Shaver, P. R. (2008). Mothers' attachment style, Their mental health, and their children's emotional vulnerabilities: A 7 - year study of children with congenital heart disease. Journal of Personality, 76(1), 31-66. http://dx.doi.org/10.1111/j.1467-6494.2007.00479.x

Church, A. H. (1993). Estimating the effect of incentives on mail survey response rates: A meta-analysis. Public Opinion Quarterly, 57(1), 62-79. http://dx.doi.org/10.1086/269355

Clark, L. A., \& Watson, D. (1991). Tripartite model of anxiety and depression: Psychometric evidence and taxonomic implications. Journal of Abnormal Psychology, 100(3), 316-336. http://dx.doi.org/10.1037/0021-843X.100.3.316

Cote, S. (2005). A social interaction model of the effects of emotion regulation on work strain. Academy of Management Review, 30(3), 509-530. http://dx.doi.org/10.5465/AMR.2005.17293692

Eley, T. C., \& Stevenson, J. (1999). Exploring the covariation between anxiety and depression symptoms: A genetic analysis of the effects of age and sex. Journal of Child Psychology and Psychiatry, 40(8), 1273-1282. http://dx.doi.org/10.1111/1469-7610.00543

Florian, V., \& Drory, Y. (1990). Mental Health Inventory (MHI): Psychometric properties and normative data in the Israeli population. Psychologia: Israel Journal of Psychology, 2(1), 26-35.

Griffeth, R. W., Hom, P. W., \& Gaertner, S. (2000). A meta-analysis of antecedents and correlates of employee turnover: Update, moderator tests, and research implications for the next millennium. Journal of Management, 26(3), 463-488. http://dx.doi.org/10.1177/014920630002600305

Howren, M. B., \& Suls, J. (2011). The symptom perception hypothesis revised: Depression and anxiety play different roles in concurrent and retrospective physical symptom reporting. Journal of Personality and Social Psychology, 100(1), 182-195. http://dx.doi.org/10.1037/a0021715

Jaccard, J. (2001). Interaction effects in logistic regression. Thousand Oaks, CA, USA: Sage Pub.

Judge, T. A. (1993). Does affective disposition moderate the relationship between job satisfaction and voluntary turnover? Journal of Applied Psychology, 78(3), 395-401. http://dx.doi.org/10.1037/0021-9010.78.3.395

Kashdan, T. B. (2004). The neglected relationship between social interaction anxiety and hedonic deficits: Differentiation from depressive symptoms. Journal of Anxiety Disorders, 18(5), 719-730. http://dx.doi.org/10.1016/j.janxdis.2003.08.001

Kopelman, R. E., Rovenpor, J. L., \& Millsap, R. E. (1992). Rationale and construct validity evidence for the job search behavior index: Because intentions (and New Year's resolutions) often come to naught. Journal of Vocational Behavior, 40(3), 269-287. http://dx.doi.org/10.1016/0001-8791(92)90051-Z

Kubzansky, L. D., Cole, S. R., Kawachi, I., Vokonas, P., \& Sparrow, D. (2006). Shared and unique contributions of anger, anxiety, and depression to coronary heart disease: A prospective study in the normative aging study. Annals of Behavioral Medicine, 31(1), 21-29. http://dx.doi.org/10.1207/s15324796abm3101_5

Larsen, J. T., \& McGraw, A. P. (2011). Further evidence for mixed emotions. Journal of Personality and Social Psychology, 100(6), 1095-1110. http://dx.doi.org/10.1037/a0021846

Lavidor, M., Weller, A., \& Babkoff, H. (2002). Multidimensional fatigue, somatic symptoms and depression. British journal of health psychology, 7(1), 67-75. http://dx.doi.org/10.1348/135910702169367

Luthans, F., Avolio, B. J., Avey, J. B., \& Norman, S. M. (2007). Positive psychological capital: Measurement and relationship with performance and satisfaction. Personnel Psychology, 60(3), 541-572. http://dx.doi.org/10.1111/j.1744-6570.2007.00083.x 
Maertz, C. P., \& Griffeth, R. W. (2004). Eight motivational forces and voluntary turnover: A theoretical synthesis with implications for research. Journal of Management, 30(5), 667-683. http://dx.doi.org/10.1016/j.jm.2004.04.001

Menard, S. (2010). Logistic regression. Thousand Oaks, CA, USA: Sage Publications.

Mineka, W., Watson, Karol E., \& Clark, L. A. (1998). Comorbidity of anxiety and unipolar mood disorders. Annual Review of Psychology, 49, 377-412. http://dx.doi.org/10.1146/annurev.psych.49.1.377

Mobley, W. H., Griffeth, R. W., Hand, H. H., \& Meglino, B. M. (1979). Review and conceptual analysis of the $\begin{array}{llll}\text { employee turnover process. Psychological Bulletin, } & \text { 86(3), }\end{array}$ http://dx.doi.org/10.1037/0033-2909.86.3.493

Moon, H., Hollenbeck, J. R., Humphrey, S. E., \& Maue, B. (2003). The tripartite model of neuroticism and the suppression of depression and anxiety within an escalation of commitment dilemma. Journal of personality, 71(3), 347-368. http://dx.doi.org/10.1111/1467-6494.7103004

Ng, T. W. H., \& Sorensen, K. L. (2009). Dispositional affectivity and work-related outcomes: A meta-analysis. $\begin{array}{lllll}\text { Journal of Applied } & \text { Social } & \text { Psychology, } & 39(6), & 1255-1287 .\end{array}$ http://dx.doi.org/10.1111/j.1559-1816.2009.00481.x

Ployhart, R. E., \& Vandenberg, R. J. (2010). Longitudinal research: The theory, design, and analysis of change. Journal of Management, 36(1), 94-120. http://dx.doi.org/10.1177/0149206309352110

Shankman, S. A., \& Klein, D. N. (2003). The relation between depression and anxiety: An evaluation of the tripartite, approach-withdrawal and valence-arousal models. Clinical Psychology Review, 23(4), 605-637. http://dx.doi.org/10.1016/S0272-7358(03)00038-2

Smoski, M. J., Lynch, T. R., Rosenthal, M. Z., Cheavens, J. S., Chapman, A. L., \& Krishnan, R. R. (2008). Decision-making and risk aversion among depressive adults. Journal of Behavior Therapy and Experimental Psychiatry, 39(4), 567-576. http://dx.doi.org/10.1016/j.jbtep.2008.01.004

Stewart, J. C., Janicki, D. L., Muldoon, M. F., Sutton-Tyrrell, K., \& Kamarck, T. W. (2007). Negative emotions and 3-year progression of subclinical atherosclerosis. Archives of General Psychiatry, 64(2), 225-233. http://dx.doi.org/10.1001/archpsyc.64.2.225

Suls, J., \& Bunde, J. (2005). Anger, anxiety, and depression as risk factors for cardiovascular disease: The problems and implications of overlapping affective dispositions. Psychological Bulletin, 131(2), 260-300. http://dx.doi.org/10.1037/0033-2909.131.2.260

Suls, J., \& Martin, R. (in press). Heart disease occurs in a biological, psychological, and social matrix: Cardiac risk factors, symptom presentation, and recovery as illustrative examples. Annals of Behavioral Medicine.

Thoresen, C. J., Kaplan, S. A., Barsky, A. P., Warren, C. R., \& Chermont, de. K. (2003). The affective underpinnings of job perceptions and attitudes: A meta-analytic review and integration. Psychological Bulletin, 129(6), 914-945. http://dx.doi.org/10.1037/0033-2909.129.6.914

Tifferet, S., Elizur, Y., Constantini, S., Friedman, O., \& Manor, O. (2008). Maternal adaptation to pediatric neurosurgical diagnosis: A growth curve analysis. Psychology \& Health, 25(2), 213-229. http://dx.doi.org/10.1080/08870440802245298

Twisk, J. W. R. (2003). Applied longitudinal data analysis of epidemiology. Cambridge, U.K.: Cambridge University Press.

Veit, C. T., \& Ware, J. E. (1983). The structure of psychological distress and well-being in general populations. $\begin{array}{lllll}\text { Journal of Consulting and Clinical Psychology, 51(5), 730-742. } & \end{array}$ http://dx.doi.org/10.1037/0022-006X.51.5.730

Wagner, C. M. (2010). Predicting nursing turnover with catastrophe theory. Journal of advanced nursing, 66(9), 2071-2084.

Watson, D. (2000). Mood and temperament. New York City, N.Y.: Guilford Press.

Watson, D., \& Walker, L. M. (1996). The long-term stability and predictive validity of trait measures of affect. $\begin{array}{lllll}\text { Journal of Personality and Social Psychology, } & \text { 70(3), } & \text { 567-577. }\end{array}$ http://dx.doi.org/10.1037/0022-3514.70.3.567

Wetherell, J. L., Gatz, M., \& Pedersen, N. L. (2001). A longitudinal analysis of anxiety and depressive symptoms. Psychology and Aging, 16(2), 187-195. http://dx.doi.org/10.1037/0882-7974.16.2.187 
Zimmerman, R. D. (2008). Understanding the impact of personality traits on individuals' turnover decisions: A

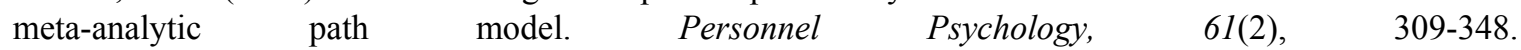
http://dx.doi.org/10.1111/j.1744-6570.2008.00115.x 